\title{
Regional structure of global warming across China during the twentieth century
}

\author{
Aigang $\mathrm{Lu}^{1, *}$, Yuanqing $\mathrm{He}^{1,2}$, Zhonglin Zhang ${ }^{1}$, Hongxi Pang ${ }^{1}$, Juan $\mathrm{Gu}^{1}$ \\ ${ }^{1}$ Cold and Arid Regions Environmental and Engineering Research Institute, Chinese Academy of Sciences, \\ Lanzhou 730000, China \\ ${ }^{2}$ Nanjing Normal University, Nanjing 210097, China
}

\begin{abstract}
A Mann-Kendall trend test was carried out using high-resolution gridded data $\left(0.5^{\circ} \times\right.$ $0.5^{\circ}$ ) of time-series for temperature, obtained from the Climatic Research Unit and the Tyndall Center. By comparing episodes of temperature change across China in the course of global warming, a regional temperature structure can be outlined: The temperature-mutation time occurs south of $35^{\circ} \mathrm{N}$, and earlier with decreasing latitude, in the $1920 \mathrm{~s}-1940 \mathrm{~s}$ warming episode, but occurs north of $35^{\circ} \mathrm{N}$, and earlier with increasing latitude, in warming since the 1970s. Temperature changes occurred almost simultaneously in eastern China, but the temperature-mutation times are widely different in western China as a result of the strong influence of the Tibetan Plateau. The Tibetan Plateau warmed much earlier in the west and northwest than in the southwest. Regional temperature change is comprehensively influenced by latitude and by landscape formations, as well as by other natural causes and human activities. Latitudinal location and landforms are major factors that influenced the temperature structure in China during the 20th century.
\end{abstract}

KEY WORDS: Temperature variation $\cdot$ Regional response $\cdot$ Climatic sensitivity $\cdot$ Land form $\cdot$ Human activities

Resale or republication not permitted without written consent of the publisher

\section{INTRODUCTION}

The temperature in the Northern Hemisphere has increased by $0.4^{\circ} \mathrm{C}$ between the 1960s and the 1980s, and in the same period temperatures on the Tibetan Plateau have increased by $0.5^{\circ} \mathrm{C}$; moreover, during 1990 to 2000 , temperature has risen by about $1^{\circ} \mathrm{C}$ (IPCC 2001). Temperatures in China have increased by $0.3^{\circ} \mathrm{C}$ between 1951 and 1990 (Ding \& Dai 1994). Using 15 different general circulation models, Jones \& Moberg (2003) estimated that the rate of annual warming over the continents between 1901 and 2000 was $0.078^{\circ} \mathrm{C}$ decade $^{-1}$ (significant at the $99.9 \%$ level). An improved understanding of global and regional climate change will be beneficial in creating sustainable development of economy, environment and society.

Temperature change in the Northern Hemisphere in the 20th century is characterized by a distinct warming, with 2 principal episodes, between the 1920s and 1940s, and since the 1970s (Fig. 1; Jones \& Moberg 2003). Ana- lyzed results of the temperature during 1901 to 2000 using a Mann-Kendall test indicate that only 1 sharp warming point (mutation point) occurred in the Northern Hemisphere, in 1936 (Fig. 2), and that no significant points were to be found during the 1970s warming episode.

Land forms (high mountains and plateaus), especially the Tibetan Plateau (Fig. 3), result in a complex pattern of climatic variations in China. In addition, because the large territory of China is influenced by several airflows, especially by the monsoon, there are different response sensitivities to global warming in different parts of China.

Here, we describe the warming structure, discuss the different responses of various locations and determine the spatial and temporal response patterns and their main causes across China in the 20th century, using high-resolution gridded data $\left(0.5^{\circ} \times 0.5^{\circ}\right)$ of time series for temperature, at a significance level of $99.5 \%$ 


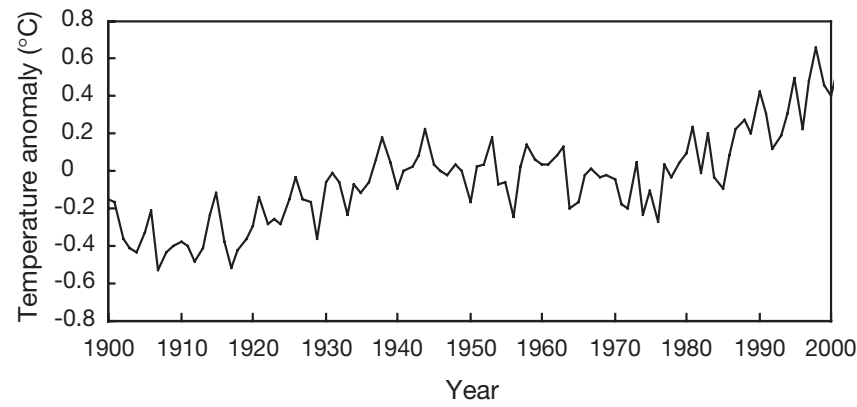

Fig. 1. Northern Hemisphere temperature variation between 1901 and 2000. Anomalies are relative to the 1961-1990 mean

\section{DATA AND METHODOLOGY}

The temperature data used in this study are highresolution gridded data $\left(0.5^{\circ} \times 0.5^{\circ}\right)$ of the calculated annual average temperatures, obtained from the Climatic Research Unit and the Tyndall Center (CRU TS 2.0) at www.cru.uea.ac.uk (University of East Anglia, Norwich, UK). The data period is $100 \mathrm{yr}(1901-2000)$.

The Mann-Kendall trend test (rank-order-based and insensitive to missing values; Mann 1945, Kendall 1955), which is one of the most widely used non-parametric tests for detecting trends in time series, is applied to analyze the temperature data. It can also be used to evaluate whether there is a significant discontinuity in data collected over a period of time.

We used the Mann-Kendall trend test in this paper to evaluate whether there is a sharp change in temperature within the $100 \mathrm{yr}$ period at different sites across China. We call a specific year in which there is a sharp change in temperature, or after which there is an abrupt change in time series, a 'mutation point', or simply a 'mutation'. For example, 1936 is the mutation point for the Northern Hemisphere average tempera- ture, and from 1936 on there is a significant increase in temperature change during the $100 \mathrm{yr}$ period.

For spatial integrity and continuity of the data in longitude and latitude, regions outside China are also considered, e.g. the entire Tibetan Plateau and neighboring regions.

\section{RESULTS AND DISCUSSION}

\subsection{Warming episodes and mutation points}

The mutation points for different sites were calculated along lines of longitude and latitude. There are 2 groups of mutation points in the 2 warming episodes, one group in the mid-latitude region and the other in the low-latitude region. This indicates that the 2 warming episodes in the 20th century behaved differently in the 2 regions. The mutation points in the 1st warming episode are more pronounced in the low-latitude area, and less obvious in the mid-latitude area - the response decreases with increasing latitude. To the north of $35^{\circ} \mathrm{N}$, the confidence level of mutation points becomes progressively lower, and in the far north there are no mutation points.

In contrast, the 2nd warming episode occurs clearly in the mid-latitude area, but not so evidently in the low-latitude area, and the confidence level is significant only north of $34^{\circ} \mathrm{N}$. In this area, significance of the confidence level decreases with decreasing latitude.

The zone around $35^{\circ} \mathrm{N}$ is the common area affected markedly by the 2 warming episodes. The differences in response to the 2 warming episodes between the 2 regions are probably caused by different mechanisms. This study analyzes the 2 warming episodes to trace the response throughout China.

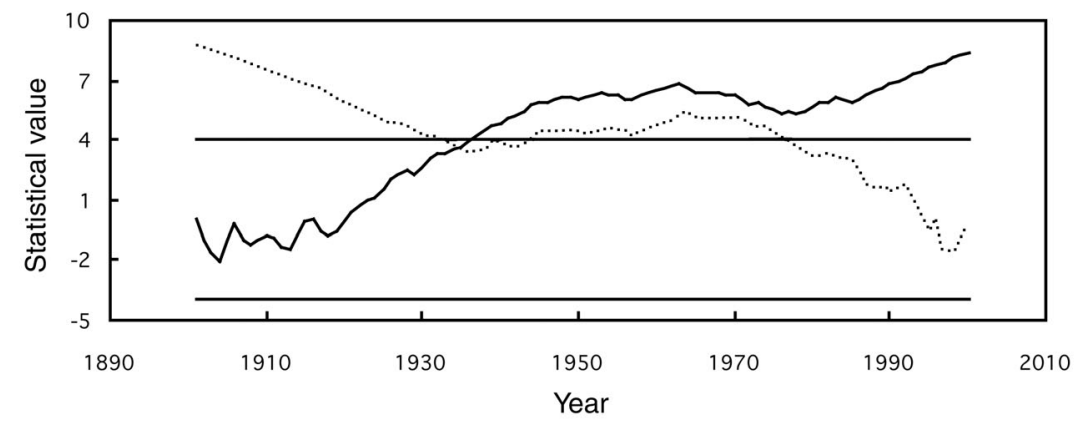

Fig. 2. Northern Hemisphere temperature between 1901 and 2000, analyzed by Mann-Kendall test. The lines at $y= \pm 4$ are the significance standard borderlines of $\alpha=0.0000634 ; C_{1}$ (solid curve): analysis of the temperature anomaly values from 1900 to $2000 ; C_{2}$ (dashed curve): analysis of the temperature anomaly values from 2000 retrograde to 1900. See Appendix 1, Sneyers (1990), Mitchell et al. (1996) for details. The point of intersection of the 2 curves in 1936 indicates initiation of a sharp warming trend

\subsubsection{North-south patterns}

As shown in Fig. 4, the 1st warming episode is obvious at low latitude: the lower the latitude, the earlier the mutation. The latest mutation point appears in the belt around $35^{\circ} \mathrm{N}$; further north, mutation disappears. The 2nd warming episode is clear in the mid-latitude area, and the higher the latitude, the earlier the mutation. The latest mutation appears at about $34-36^{\circ} \mathrm{N}$ in eastern China, and further south there is no mutation. The latest mutations for both the warming episodes occur at about $35^{\circ} \mathrm{N}$. However, on the western Tibetan Plateau (west of about $92^{\circ} \mathrm{E}$ ) in the 2nd warming episode the lat- 


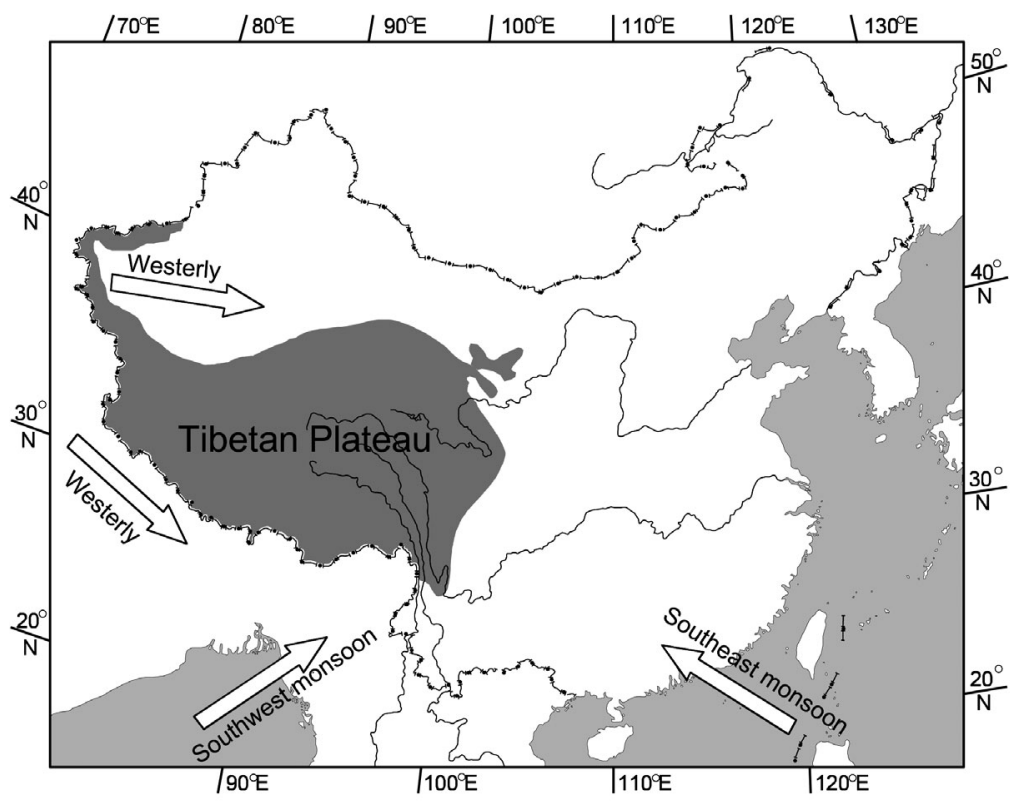

Fig. 3. General pattern of air flows and land forms in China the location of the $0^{\circ} \mathrm{C}$ isotherm in winter, a boundary between the warm-temperate zone and the subtropical zone, and it is also the annual $800 \mathrm{~mm}$ precipitation line. The hydrology, vegetation and agrotypes, and farming systems, are completely different on either side of the $35^{\circ} \mathrm{N}$ divide. A similar climate divide along $35^{\circ} \mathrm{N}$ was also found by Zhai \& Ren (1997), Chen et al. (1991, 1999), Araguas-Araguas et al. (1998), and Li et al. (2000). An asynchronous climate event near $35^{\circ} \mathrm{N}$ found by Wang et al. (2003) can be explained by the mutation structure described here.

\subsubsection{East-west patterns}

The difference of the temperature mutations is not very marked in eastern China, which is influenced by the SE monsoon and has a generally flat land form (Fig. 5). The est mutation begins at $32^{\circ} \mathrm{N}$, and it occurs at a much lower latitude along $85^{\circ} \mathrm{E}$, but not in other areas at that latitude. Most of the mutations in the 1st warming episode occur south of $35^{\circ} \mathrm{N}$, and those in the 2nd warming episode stop at $30^{\circ} \mathrm{N}$, except in the area along $85^{\circ} \mathrm{E}$, where mutation stops at $30^{\circ} \mathrm{N}$ in the 1 st warming and continues to $25^{\circ} \mathrm{N}$ in the 2nd episode. Except for the area along $85^{\circ} \mathrm{E}$, the belt along $35^{\circ} \mathrm{N}$ responds to both warming episodes with very high confidence levels. Fig. 4 also shows that at a given longitude the earlier mutation occurs in the 1st warming episode, the later it occurs in the 2nd warming episode. In summary, $35^{\circ} \mathrm{N}$ latitude is a geographical boundary in the response to the 2 warming episodes.

The distribution of the mutations resulting from global warming is probably caused by the differences in solar radiation at different latitudes. The most intensive radiation from the sun is focused on the belt between 10 and $30^{\circ} \mathrm{N}$, where the solar radiation balance is positive. From $30^{\circ} \mathrm{N}$ northward, solar-radiation balance is negative, and the radiation intensity declines with increasing latitude: north of $35^{\circ} \mathrm{N}$, the sensitivity of the different regions to global warming may increase with increasingly continental character of an area. Due to the distribution of the land and water masses around China, continentality generally increases with latitude. The Qinling-Huaihe River line, which is at around $35^{\circ} \mathrm{N}$, has always been an important natural climate divide in China; it is relatively late response of the coastal region is possibly a result of the oceanic influence, as mutation occurred later at lower latitude and near the ocean. Mutation occurred later in the region influenced by the SW monsoon, and it occurred much earlier in NW China due to the influence of the Tibetan Plateau in SW China. Long-term studies of climate change, e.g. research of ice cores mostly from the areas north of $35^{\circ} \mathrm{N}$, have shown that the northern Tibetan Plateau has always been much more sensitive to climate change than eastern China (He et al. 2004). The climate sensitivity of the Tibetan Plateau is attributed to its high altitude (Stuijts et al. 1988, Colinvaux et al. 1996, Liu et al.

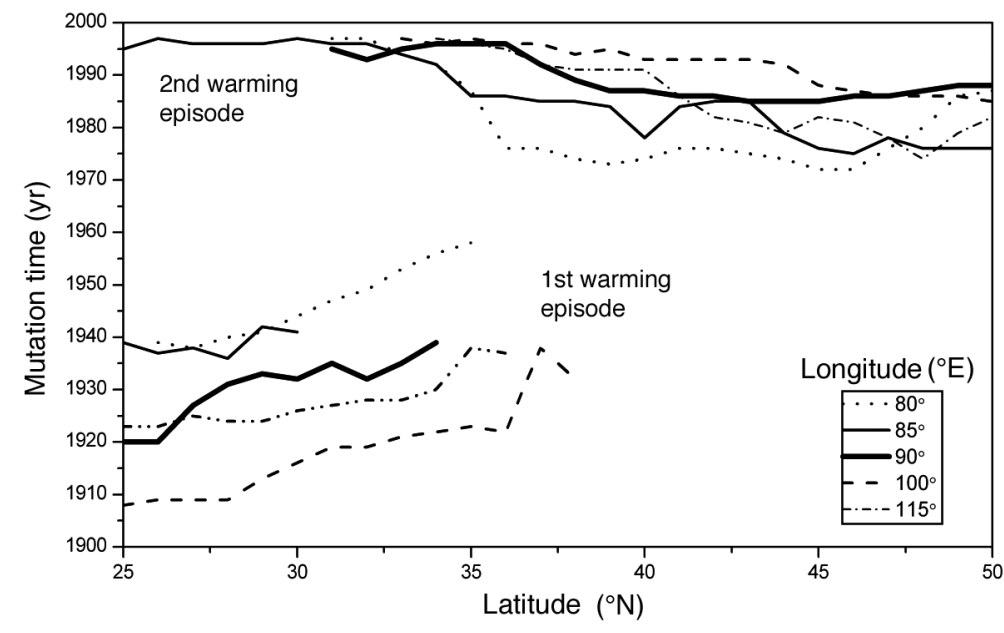

Fig. 4. Temperature mutation time: latitudinal distribution at different longitudes 


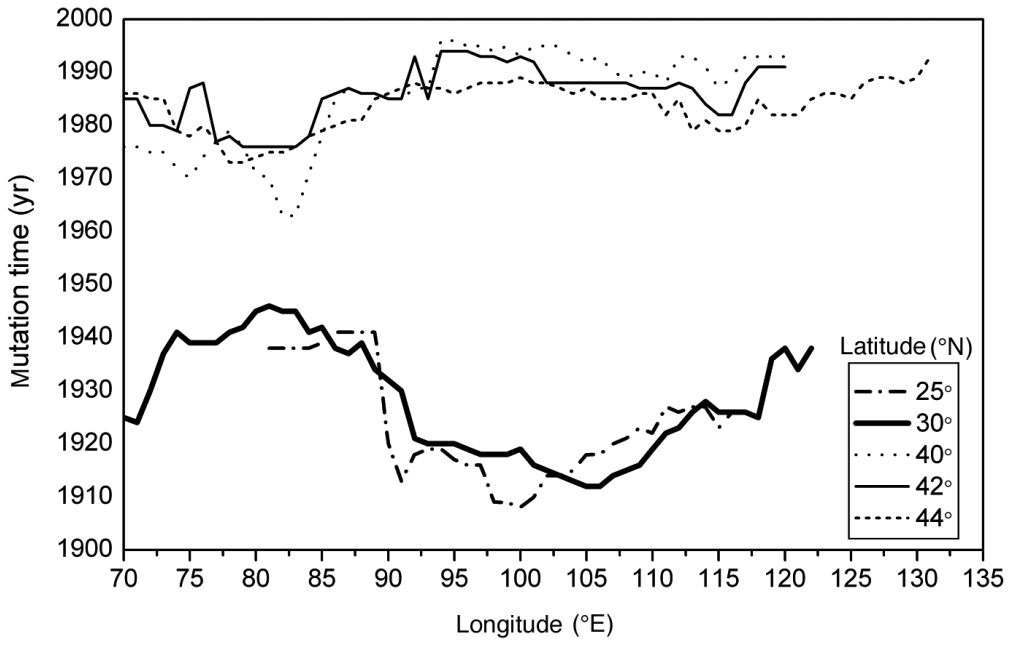

Fig. 5. Temperature mutation time: longitudinal distribution at different latitudes

there was a strong relation between the Tibetan Plateau heat flux and the temperature in NW China. Therefore, the Tibetan Plateau, as the world's highest plateau, plays a very important role in influencing the climate of China, especially for western China.

\subsection{Global warming, and economic development in China}

Global warming is a complex process, and it results from both natural and human processes. The long-term (multi-decade) variation of the Northern Hemisphere continental air temperature is negatively correlated with the long-term variation of solar activity during the period of systematic instrumental temperature measurements

1997, Yao et al. 2000). However, this cannot account for the temperature lag to the south of the Plateau. There is a very regular mutation distribution in eastern China, as mutation occurred earlier at higher latitudes, and Fig. 5 also shows that the temperature mutations in SE China (east of $92^{\circ} \mathrm{E}$ and south of $35^{\circ} \mathrm{N}$ ) occurred much earlier (1910-1920) than was the rule in the Northern Hemisphere (1936).

Temperatures in SW China declined from the 1950s to the 1980s (Ding \& Dai 1994), more than 10 yr later than the North Hemisphere average temperature decline from the 1940s to the 1970s. This agrees with the distribution shown in Fig. 5, and it probably results from the fact that the Tibetan Plateau constitutes a barrier to the north-south airflow, so that the area south of the Plateau is scarcely affected by the higher-latitude climate.

The eastern fringe of the Tibetan Plateau reaches eastward of $100^{\circ} \mathrm{E}$. However, the lag of the temperature mutation on the northern Plateau occurs from $92^{\circ} \mathrm{N}$ westward, and that on the southern Plateau begins further westward (Fig. 5). The western fringe of the Tibetan Plateau is around $75^{\circ} \mathrm{E}$, but its influence on the climate reaches westward to $70^{\circ} \mathrm{E}$. All in all, the Tibetan Plateau influences the areas to the west, whereas the eastern Plateau is strongly influenced by the SE monsoon. In this region, the Hengduan Mountains alternate with valleys having a SE-NW orientation, which favors an influence of the SE monsoon on the eastern Plateau. A monsoon influence is lacking in the western Plateau; here, and on the NW Plateau the predominant influence is from the westerly winds.

Using temperature data for the last 40 yr from 84 stations on the Tibetan Plateau, Ma \& Li (2003) showed that there was a marked climatic difference between the western plateau and the eastern plateau. As reported by Li et al. (1997) on the basis of EOF and REOF methods,
(1861 to 1989; Friis-Christensen et al. 1991). On the other hand, Laut (2003) analyzed a number of published graphs which have played a major role in debates on the relationship between temperature and solar activity, showing that the strong correlations on these graphs were obtained by incorrect handling of the physical data. An increasing body of research attributes global warming to human activities. Similarly, Jones \& Mann (2004), by comparing empirical evidence with proxy-based reconstructions, demonstrated that natural factors explain the major surface temperature changes of the past millennium (including hemispheric means and some spatial patterns) relatively well through the 19th century. Only anthropogenic forcing of climate, however, can explain the anomalous warming in the late 20th century. McKitrick \& Michaels (2004) obtained a similar result, using both monthly surface temperature records for 1979 to 2000 from 218 stations in 93 countries and the corresponding IPCC gridded data,: The spatial surface temperature trends are significantly correlated with non-climatic factors, including economic activity and sociopolitical characteristics of the region. Demirba (2003) has argued that $\mathrm{CO}_{2}$ and $\mathrm{CO}$ are the main greenhouse gases (GHGs) associated with global warming. At the present time, coal is responsible for 30 to $40 \%$ of world $\mathrm{CO}_{2}$ emissions from fossil fuels. Currently, it is estimated that $\mathrm{CO}_{2}$ is responsible for about $50 \%$ of the anthropogenic greenhouse effect. Several other gases, e.g. $\mathrm{CH}_{4}, \mathrm{CFCs}$, halogens, $\mathrm{N}_{2} \mathrm{O}, \mathrm{SO}_{2}$, ozone and peroxyacetylnitrate, which are produced by industrial and domestic activities, also contribute GHGs (Dincer 2001).

In China, numerical experiments by Fu (2003) have shown that changes in land cover have brought about significant changes in the East Asian monsoon by altering the complex exchanges of water and energy 
between the surface and the atmosphere. Therefore, it is very likely that an anthropogenic modification of the monsoon system has occurred in the history of civilization. Both the summer and winter monsoons are crucial for south-north heat transport. The regional temperature response of China to global change is thus influenced by changes in the monsoons. In addition, the uneven urbanization structure of different regions may affect the response to climate change. With increasing urbanization in China, rural household energy consumption increased from 26200 to $33700 \mathrm{Mtce}$ (megatons coal equivalent) in 1980-1986, with an annual growth of $1.6 \%$. Commercial energy and electricity consumption increased at an annual rate of 7.5 and $16.3 \%$, respectively. Household energy consumption per capita also grew from $329 \mathrm{kgce}$ in 1980 to $370 \mathrm{kgce}$ in 1995 (Wang \& Feng 2001). China is the world's second largest producer of GHGs, and its emissions will increase substantially in the future. Rapid economic expansion will require higher inputs of primary energy, and the continuing heavy reliance on coal will more than double China's recent $\mathrm{CO}_{2}$ emissions. Providing enough food for a population that is still growing at high absolute rates will require further intensification of farming and result in higher releases of $\mathrm{CH}_{4}$ and $\mathrm{N}_{2} \mathrm{O}$. Consequently, China will become the world's largest emitter of GHGs as early as the 2010s (Smil 1994).

Anthropogenic impacts on global climate change are increasing worldwide, and the regional effects are complicated. The causes of the different intensities of the warming episodes in the 2 areas of China, and the human contribution to the regional response require further investigation.

\section{CONCLUSIONS}

(1) The southern part of China was more sensitive to the 1st warming episode beginning in the 1920s, whereas central China was more sensitive to the 2nd episode beginning in the 1970s.

(2) Temperature mutations in southern China occurred much earlier than in the Northern Hemisphere in general. Temperature mutation has lagged in the region around $35^{\circ} \mathrm{N}$ (Fig. 6C), and it has occurred earlier with increasing distance from the $35^{\circ} \mathrm{N}$ divide.

(3) The influence of the Tibetan Plateau has enhanced the sensitivity of western China to the global

temperature change, causing the temperaturemutation to occur later in SW China and earlier in NW China (Fig. 6A,B).

(4) The general pattern of the temperature responses along the latitude can be attributed to the influences of the land forms and the ocean, and the temperature response along the longitude was very likely caused by the solar radiation patterns between 20 and $35^{\circ} \mathrm{N}$, and by the continental effects in the areas north of $35^{\circ} \mathrm{N}$.

(5) Although human activities are contributing more and more to climate change, land forms and latitude effects seemed to be dominating factors influencing the climate of China in the 20th century.

Acknowledgements. This study was supported by the Chinese Natural Science Foundation 'Western Great Project' (90302006), the Hundred Talents Project (CAS2002-43) and the Knowledge-Innovation Programs (40121101).

\section{LITERATURE CITED}

Araguas-Araguas L, Froehlich K, Rozanski K (1998) Stable isotope composition of precipitation over Southeast Asia. J Geophys Res 103(22):28721-28742

Chen L, Zhu Q, Luo H (1991) Eastern Asia Monsoon. Meteorology Press, Beijing, p 189-191

Chen L, Liu J, Zhou X, Wang P (1999) Impact of uplift of Qinghai-Xizang Plateau and change of land-ocean distribution on climate over Asia. Quat Sci 4(7):314-329

Colinvaux PA, De Oliveira PE, Moreno JE (1996) A long pollen record from lowland Amazon: forest and cooling in glacial times. Science 274:85-88 
Demirba A (2003) Energy and environmental issues relating to greenhouse gas emissions in Turkey. Energy Convers Manage 44(1):203-213

Dincer I (2001) Environmental issues: I. Energy utilization. Energy Source 23:69-81

Ding Y, Dai X (1994) Temperature variation in China during the last 100 years. Acta Meteorol 20(12):19-26

Friis-Christensen E, Lassen K (1991) Length of the solar cycle: an indicator of solar activity closely associated with climate. Science 254:698-700

Fu C (2003) Potential impacts of human-induced land cover change on East Asia monsoon. Global Planet Change 37(3-4):219-229

He Y, Theakstone WH, Zhang Z, Zhang D, Yao T, Chen $\mathrm{T}$, Shen Y, Pang H (2004) Asynchronous Holocene climatic change across China: a review. Quat Res 61(1):52-63

IPCC (2001) Climate change 2001: impacts, adaption, and vulnerability. Summary for policymakers. Report of Working Group II of the Intergovernmental Panel on Climate Change, Cambridge University Press, Cambridge

Jones PD, Mann ME (2004) Climate over past millennia. Rev Geophys (doi:10.1029/2003RG000143)

Jones PD, Moberg A (2003) Hemispheric and large-scale surface air temperature variations: an extensive revision and an update to 2001. J Clim 16:206-223

Kendall MG (1955) Rank correlation methods. Griffin, London

Laut P (2003) Solar activity and terrestrial climate: an analysis of some purported correlations. J Atmos Solar-Terrestrial Phys 65(7):801-812

Li D, Xie J, Zhao Z, Fei X, Li Y (1997) A diagnosis and numerical experiment of responses about summer temperature change in the Qinghai-Xizang Plateau. Clim Environ Res 2(4)377-386

Li S, Tang H, Ma Y, Zhang J (2000) Analyses on monthly mean temperature and anomalous distribution over Qinghai-Xizang Plateau in winter and summer. Plateau Meteorol 19(4):520-529
Liu X, An Z, Wu X (1997) East Asian paleoclimates of the last glacial maximum in an atmospheric general circulation model and from geological records. Proc 3rd Int Geol Conf 21:156-171

Ma X, Li D (2003) Analyses on air temperature and its abrupt change over Qinghai Xizang Plateau in modern age. Plateau Meteorol 22(5):508-512

Mann HB (1945) Nonparametric tests against trend. Econometrica 13:245-259

McKitrick R, Michaels PJ (2004) A test of corrections for extraneous signals in gridded surface temperature data. Clim Res 26:159-173

Mitchell JM, Dzezerdzeeskii B, Flohn H, Hofmeyer WL, Lamb HH, Rao KN, Wallen CC (1996) Climatic change. WMO Tech Note 79, World Meteorological Organization, Geneva

Smil V (1994) China's greenhouse gas emissions. Global Environ Change 4(4):325-332

Sneyers R (1990) On the statistical analysis of series of observations. WMO Tech Note 143 No. 415. World Meteorological Organization, Geneva

Stuijts I, Newsome JC, Flenley JR (1988) Evidence for the late Quaternary vegetational change in the Sumatran and Javan highlands. Rev Paleobot Palynol 55:207-216

Wang N, Yao T, Pu J, Zhang Y, Sun W, Wang Y (2003) Variations in air temperature during the last 100 years revealed by $\delta$ (18) O in the Malan ice core from the Tibetan Plateau. Chin Sci Bull 48(19):2134-2138

Wang X, Feng Z (2001) Rural household energy consumption with the economic development in China: stages and characteristic indices. Energy Policy 29(15):1391-1397

Yao T, Liu X, Wang N (2000) A study on the amplitude of climatic variation in Tibetan plateau. Chin Sci Bull 45(1): 98-105

Zhai P, Ren F (1997) On changes of China's maximum and minimum temperatures in the recent 40 years. Acta Meteorol Asinica 55(4):418-429

Appendix 1. Mann-Kendall rank correlation statistics

For each element $x_{i}$ the number of $r_{i}$ elements $x_{j}$ preceding it $(i>j)$ is calculated so that $\operatorname{rank}\left(x_{i}\right)>\operatorname{rank}\left(x_{i}\right)$. The test statistic is calculated as:

$$
\operatorname{rank} s_{k}=\sum_{i=1}^{k} r_{i}(k=2,3, \ldots, n)
$$

where $\quad r_{i}\left\{\begin{array}{l}+1 \text { when } x_{i}>x_{j} \\ 0 \text { else }\end{array}(j=1,2, \ldots, i)\right.$

The distribution function of $t$ is assumed to be asymptotically Gaussian with:

$$
E\left(s_{k}\right)=\frac{n(n-1)}{4} \text { and } \operatorname{Var}\left(s_{k}\right)=\frac{n(n-1)(2 n+5)}{72}
$$

where $E\left(s_{k}\right)$ is the mathematical expectation of $s_{k}$, simply, the average of accumulative $s_{k}$, and $\operatorname{Var}\left(s_{k}\right)$ is variance of $s_{k}$.

Two-sided test. $H_{0}$ is rejected for high values of $\left|U F_{k}\right|$

$$
U F_{k}=\frac{\left[s_{k}-E\left(s_{k}\right)\right]}{\sqrt{\operatorname{Var}\left(s_{k}\right)}}(k=1,2, \ldots, n)
$$

The graphical representation of all $U F_{k}, 1 \leq k \leq N$, is denoted as $C_{1}$. The same principle is applied to the retrograde series, in order to localize the beginning of the change. The graphical representation of the retrograde series $U F^{\prime}{ }_{k}$ is denoted as $C_{2}$. The intersection of the curves $C_{1}$ and $C_{2}$ localizes the change (which represents an abrupt climatic change) and allows the identification of the year when a trend or change begins. Absolute values of $F_{k}$ $>1.96$ indicate a trend or a change in the time series.

Similar graphical analysis was conducted for $U F_{k}$ and $U F^{\prime}{ }_{k}$ (curves $C_{1}$ and $C_{2}$ respectively) to identify the intersection of the curves, thus allowing detection of the initiation of a trend or change. The graphical representations for the mean annual values of temperature for the sites of $92^{\circ} \mathrm{E}, 50^{\circ} \mathrm{N}$ and $32^{\circ} \mathrm{N}, 85^{\circ} \mathrm{E}$ are given in Figs. A1 \& A2, respectively. 
Appendix 1 (continued)

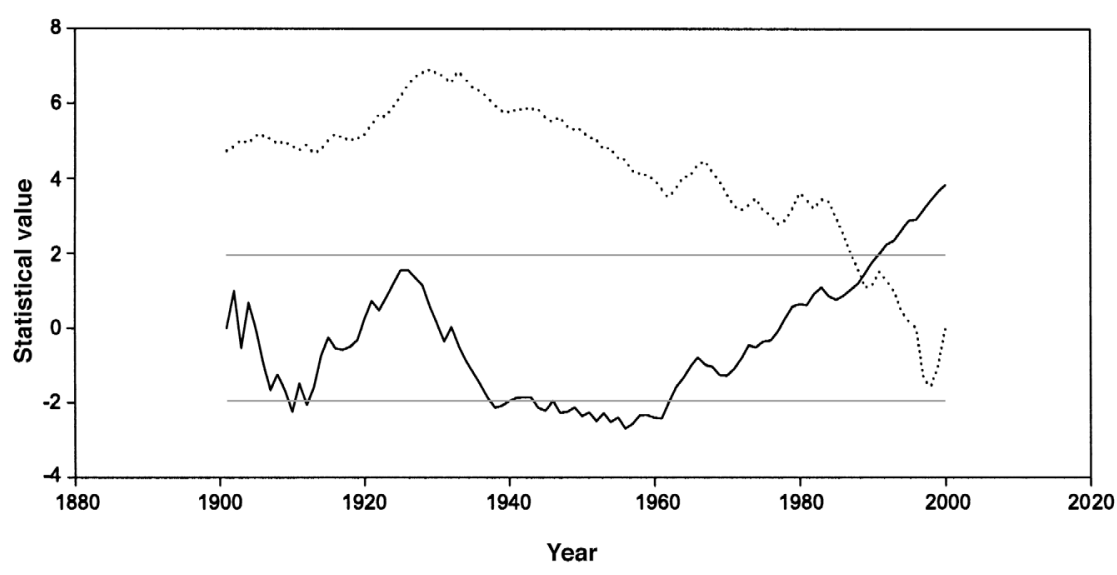

Fig. A1. Values of the sequential version of Mann-Kendall test $\left(C_{1},-, C_{2} \cdots \cdots\right)$ for annual mean temperature at $92^{\circ} \mathrm{E}, 50^{\circ} \mathrm{N}$, for 1901-2000. Grey lines at $y= \pm 1.96$ show the standard significance borderlines of $\alpha=0.05$

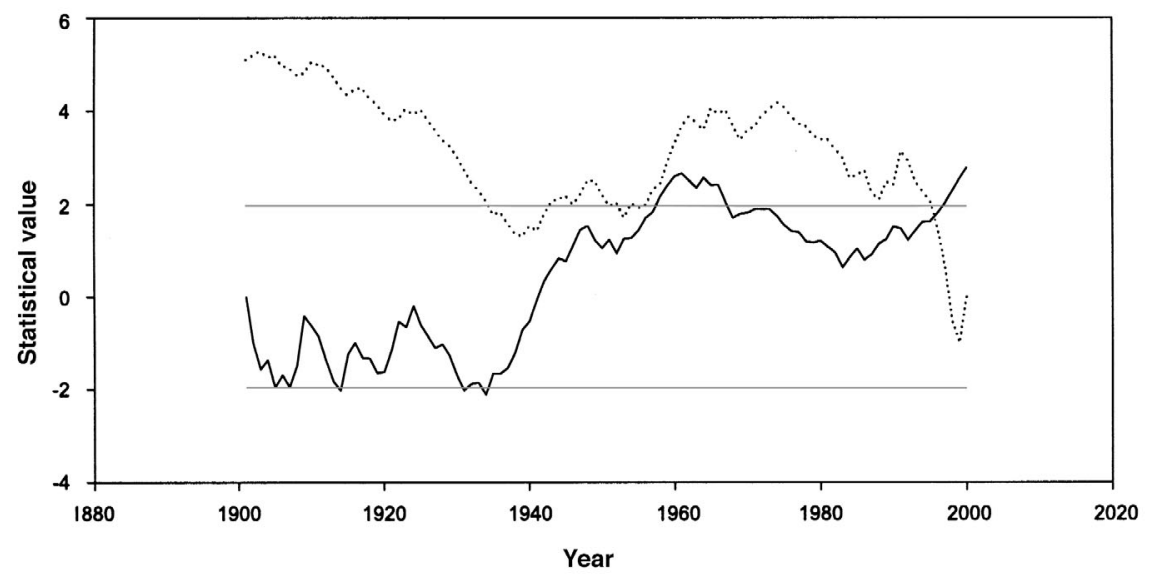

Fig. A2. Values of the sequential version of the Mann-Kendall test $\left(C_{1}-, C_{2} \cdots \cdots\right)$ for annual mean temperature at $32^{\circ} \mathrm{N}$, $85^{\circ} \mathrm{E}$, for 1901-2000. Grey lines at $y= \pm 1.96$ show the standard significance borderlines of $\alpha=0.05$

Editorial responsibility: Madhav L. Khandekar, Ontario, Canada
Submitted: June 12, 2004; Accepted: October 8, 2004

Proofs received from author(s): November 23, 2004 